\title{
Salvia verticillata L. (Dadırak)'nın Tohum Dormansisinin Kırılmasında Farklı Uygulamaların
} Etkileri

\section{Ayşe Özlem TURSUN iD}

Malatya Turgut Özal Üniversitesi, Battalgazi MYO, Battalgazi, Malatya

https://orcid.org/0000-0003-2495-0978

$\bowtie$ :ozlem.tursun@ozal.edu.tr

\section{ÖZET}

Lamiaceae familyası içerisinde en büyük cins olan Salvia türleri dünyada geniş bir alana yayılmış olup 900 kadar adaçayı türü bulunmaktadır. Salvia cinsine ait tohumlarda dormansi söz konusudur ve tohum kabuğundaki müsilaj maddesi çimlenmeyi engelleyici önemli bir faktördür. Bu çalışma, Salvia verticillata’nın tohumlarındaki dormansinin kırılması üzerine farklı uygulamaların etkisini belirlemek amaciyla tesadüf parselleri deneme desenine göre 4 tekerrürlü olarak kurulmuştur. Çalışmada denemeler 14 saat 26 ${ }^{\circ} \mathrm{C}$ ve 10 saat $16{ }^{\circ} \mathrm{C}$ olarak tamamen aydınlık, karanlık ve 14 saat aydınlık ve 10 saat karanlık olacak şekilde kurulmuştur. Çalışma sonucunda en yüksek tohum çimlenmesi \%74 ile 2000 ppm giberellik asitin $\left(\mathrm{GA}_{3}\right)$ 26/16 ${ }^{\circ} \mathrm{C}$ tamamen karanlık uygulamasından elde edilmiştir. S. verticillata tohumları \%96'lk etanolde 30 dakika tutulduktan sonra 14 saat aydinlı ve 10 saat karanlık ortam, \%96'lık etanolde 120 dakika tutulduktan sonra aydınlık, karanlık ve 14 saat aydınlık ve 10 saat karanlık ortam, hidroklorik asitte 60 dakika tutulduktan sonra 14 saat aydınlık ve 10 saat karanlık uygulamaları ile \%15'lik sodyum hipokloritte 10 dakika tutulduktan sonra aydınlık uygulamasında çimlenme olmamıştır. Bu sonuçlar ışığında giberellik asit uygulamalarının adaçayı tohumlarındaki dormansinin kırılmasında etkili olup çimlenme oranını arttırdığı ve yeni fide elde etmede önemli olacağı anlaşılmıştır.

\section{Araştırma Makalesi}

Makale Tarihçesi

GelişTarihi : :04.05.2019

Kabul Tarihi : 24.06.2019

\section{Anahtar Kelimeler}

Salvia verticillata

Giberellik asit

Dormansi

\section{The Effects of Different Applications on Breaking Dormancy of Salvia verticillata L. (Lilac Sage)}

\section{ABSTRACT}

Salvia species, the largest genus in the Lamiaceae family, are spread over a large area, with about 900 species in the world. There is dormancy in seeds of Salvia genus and having mucilage-like seedcoats is an inhibiting factor for germination. This study was conducted with 4 replications as a randomized plot design in order to determine the effect of different applications on the breakage of dormancy in the seeds of Salvia verticillata L. Experiments were set up at $26 / 16{ }^{\circ} \mathrm{C}$, completely light, completely dark and 14 hours in light and 10 hours in dark conditions. As a result of the study, the highest seed germination was obtained from $74 \%$ to $2000 \mathrm{ppm}$ of giberic acid completely dark application at $26 / 16$ oC. There was no germination of seeds in $96 \%$ ethanol at 30 minutes in light/dark, $96 \%$ ethanol at 120 minutes in light, dark and light/dark, hydrochloric acid at 60 minutes in light/dark and $15 \%$ sodium hypochlorite at 10 minutes light. In the light of these results, it was concluded that giberalic acid applications would be important to increase the germination rate of sage seeds and obtain new seedlings.

\section{Research Article}

$\begin{array}{ll}\text { Article History } & \\ \text { Received } & : 04.05 .2019 \\ \text { Accepted } & : 24.06 .2019\end{array}$

Keywords
Salvia verticillata
Gibberellic acid
Dormancy

To Cite : Tursun AÖ 2019. Salvia verticillata L. (Dadırak)'nın Tohum Dormansisinin Kırılmasında Farklı Uygulamaların Etkileri. KSÜ Tarım ve Doğa Derg 22(Ek Sayı 1): 30-37. DOI: 10.18016/ksutarimdoga.vi.560605.

\section{GİRIŞ}

Dünyada 236 cins ve 7133 tür ile geniş yayılış gösteren Lamiaceae familyasına ait bitkiler (Harley ve ark., 2004) Akdeniz ülkeleri başta olmak üzere Avustralya, Güney Batı Asya ve Güney Amerika'da 
yoğun yayılış göstermektedir (Temel, 2000). Bu familyaya ait bitkilerin çoğunluğu uçucu yağlar ve sekonder bileşiklerce zengin olması nedeniyle başta tıp olmak üzere pek çok alanda kullanılması açısından oldukça önemlidir (Kahraman ve ark., 2009). Adını iyileştirici anlamına gelen salvare sözcüğünden alan Salvia (Amiri, 2007), Lamiaceae familyasının en önemli cinslerinden biridir (Delamare ve ark., 2007; Mayekiso ve ark., 2008, Tepe ve ark., 2004, Amiri, 2007, Kotan ve ark., 2008). 900 kadar olan Salvia türleri (Delamare ve ark., 2007; Kotan ve ark., 2008) 106 taksonla (99 türe bağlı 8 alttür ve 6 varyete) Türkiye'nin en büyük ikinci cinsidir (Anonim, 2017). Halk arasında adaçayı olarak bilinen çeşitli şekillerde değişik hastalıklara karşı kullanılan Salvia türleri hem tıp alanında hem de ekonomik açıdan önemlidir (Bayram, 2001; Amiri, 2007; Yılmaz ve Güvenç, 2007). Salvia türleri çalı formunda, tek yıllık, iki yıllık ve çok yıllık bitkileri içermektedir. Salvia cinsine bağll Salvia verticillata L. otsu çok yıllık bir tür olup 15-70 cm boya ulaşabilmektedir (Özer, 2016). Antioksidan (Tosun ve ark., 2009; Sarbanha ve ark., 2011; Orhan ve ark., 2013), antimikrobiyal (Kunduhoglu ve ark., 2011), antidiabetik etkiye (Eidi ve ark., 2011) ve antikolinesteraz aktiviteye (Matkowski ve ark., 2008, Kunduhoglu, 2011; Orhan ve ark., 2013) sahiptir ve çeşitli polifenoller, uçucu yağlar ve diterpenoidler içerdiği bilinmektedir (Matkowski ve ark., 2008).

Tohum çimlenmesi bitki yaşamının en kritik aşamalarından biridir (El-Keblawy ve Al-Rawai, 2005). Bitki yetiştirme döngüsünde önemli bir etkiye sahip olan tohum çimlenme süreci (Bu ve ark., 2008) bazı bitkilerde dormansi (uyku hali) nedeniyle geçici olarak ertelenmektedir. Uygun koşullarda belirli bir zamanda çimlenemeyen tohumlar için dormansi terimi kullanılır (Hilhorst, 1995, Baskin ve Baskin 1993). Dormansi ve tohum çimlenmesi bitkilerin büyümesini ve gelişimini etkileyen genetik faktörlere ve çevre koşullarına bağlı olarak değişmektedir (Sarmandnia, 1996). Tohum kabuğu, embriyo ve tohumda çimlenmeyi inhibe edici maddelerin varlığ tohum dormansisini etkileyen faktörler arasındadır (Latifi, 2001; Elamin ve ark., 2013). Ayrıca, ışık ve sıcaklık da çimlenmeyi etkileyen önemli faktörler arasında yer almaktadır (Hazerbroek ve Metzger, 1990).

Tıbbi bitkilerin tohumlarının çoğu çevresel koşullara ekolojik uyumlulukları bakımından değişkendir. $\mathrm{Bu}$ nedenle tıbbi bitkilerin tohum çimlenmesi için optimal şartları yaratmak ve dormansiyi etkileyen eko-fizyolojik faktörleri tanımlamak onların kültür ve üretimi için gereklidir (Khakpoor ve ark., 2015). Tohumların kalite özellikleri hakkında bilgi verilmesi ve tohumların çimlenmesi için en uygun koşulların yaratılması ekimi ve çoğaltılması için önemlidir (Ghasemi Pirbaloti ve ark., 2007).
Salvia cinsine ait tohumların kabuklarinda bulunan müsilajımsı madde dormansiye neden olmaktadır (Özcan ve ark., 2014). S. verticillata tohumlarının düşük çimlenme oranı yüzünden bu bitkinin dormansi ve çimlenmesini etkileyen faktörlerin incelenmesi hayati önem taşımaktadır (Khakpoor ve ark., 2015). Bu nedenlerden dolayı bu çalışma, düşük tohum çimlenmesine sahip olan $S$. verticillata 'nın sahip olduğu dormansiyi kırarak çimlenme oranını arttırmak için farklı uygulamaların etkisini ve çimlenme hızını belirlemek amacıyla yapılmıştır.

\section{MATERYAL ve METOT}

Denemede kullanılan tohumlar Malatya İnönü Üniversitesi Battalgazi Kampüsü içerinden 2017 yaz sezonunda toplanmıştır. Toplanan tohumlar oda sicaklığında $\left(25{ }^{\circ} \mathrm{C}\right)$ denemeler kuruluncaya kadar kese kağıtları içerisinde muhafaza edilmiştir. Denemede 1 aylık taze tohumlar kullanılmış olup, yüzey sterilizasyonu \%1'lik sodyum hipoklorit çözeltisinde 1 dakika bekletildikten sonra steril saf su ile yıkanarak yapılmıştır.

Denemeler İnönü Üniversitesi Battalgazi MYO iklim odasında tesadüf parselleri deneme desenine göre 4 tekerrürlü olarak 14 gün boyunca 14 saat $26{ }^{\circ} \mathrm{C}+10$ saat $16{ }^{\circ} \mathrm{C}$ olarak aydınlık karanlık ile 14 saat aydınlık + 10 saat karanlık olacak şekilde 2017 yılında kurulmuştur.

Tohumların çimlenmesine etkilerini belirlemek, tohumlarda bulunan dormansiyi kurabilmek ve uygulamalar arasındaki farkları ortaya koymak için farklı kimyasal maddeler kullanılmıştır. $\mathrm{Bu}$ uygulamalar; kontrol, saf su (24, 72 ve 120 saat), $\% 15$ 'lik sodyum hipoklorit (10, 20 ve 30 dakika), $\% 0.5$ 'lik sodyum hipoklorit $(24,72$ ve 120 saat), $\% 96 ' l$ 'lk etanol (30, 60 ve 120 dakika), \%3'lük etanol (24, 72 ve 120 saat), $120 \mathrm{~W}$ (watt)'llk mikrodalga (10, $20,45,90$ ve 180 saniye), \%96'lık sülfürik asit (60, 120 saniye ve 15,30 dakika), \%32'lik hidroklorik asit $(5,15,30$ ve 60 dakika $)$ ve giberellik asit $(250,500$, 1000 ve 2000 ppm) olarak adaçayı tohumlarına uygulanmıştır. Giberallik asit uygulaması hariç diğer uygulamalarda adaçayı tohumları belirtilen süre kadar denemelerden önce bekletilmiştir. Her bir uygulama için her petriye giberellik uygulamaları hariç $6 \mathrm{ml}$ saf su konulmuştur. Giberellik asit uygulamalarında ise her petriye $6 \mathrm{ml}$ çözeltilerden deneme boyunca ihtiyaç oldukça uygulanmıştır. Denemelerde her petri kabına iki kat filtre kağıdı yerleştirilmiş ve 25 'er adet tohum bırakılmıştır.

Bütün petrilerde çimlenen tohumlar (1 $\mathrm{mm}$ radikula/kökçük çıkışı olduğunda çimlenmiş kabul edilmiştir) 14 gün boyunca günlük olarak sayılmış ve çimlenmiş tohumlar petri kaplarından uzaklaştırılmıştır. Çalışmada, 14 gün sonunda petri kaplarından ayrılan çimlenmiş tohumların (radikula/kökçük görülünce) sayısı her bir uygulama 
için kaydedilmiştir. Her uygulama için çimlenme oranları \% olarak hesaplanmıştır.

Denemeler sonucunda aydınlık, karanlık ve aydınlık/karanlık ortamlarda çimlenen tohumların çimlenme oranları ile $\mathrm{T}_{50}$ (Çimlenen tohumların \% 50 'sinin çimlenmesi için geçen süre) ve $\mathrm{T}_{90}$ (Çimlenen tohumların \% 90'sinin çimlenmesi için geçen süre) değerleri hesaplanmıştır.

Denemede toplam çimlenen tohumların yüzde oranları için istatistiki analizler her üç ortam (aydınlık, karanlık ve aydınlık/karanlık) için kendi içerinde yapılmış ve sonuçlar değerlendirilmiştir. İstatistiki analizler SPSS programı kullanılarak ve uygulamalar arasında görülen farklılıklarının gruplandırılmaları ise LSD testine göre 0.05 düzeyinde belirlenmiştir.

\section{BULGULAR ve TARTIŞMA}

Deneme sonucunda $S$. verticillata tohumlarmin çimlenmesi üzerine farklı uygulamalar ve ortamların (aydınlık, karanlık ve aydınlık/karanlık) etkilerine ait sonuçlar Çizelge 1'de verilmiştir. Her üç ortamda da uygulamalar arasında fark önemli bulunmuştur. En yüksek çimlenme oranı karanlık ortamda 2000 ppm giberellik asit uygulamasından (\%74) elde edilmiştir. Bunu yine aynı uygulamanın aydınlık/karanlık uygulaması (\%71) takip etmiştir. Giberellik asit uygulamalarında uygulama dozu artıkça çimlenme oranında artış olmuştur. Aydınlık, karanlık ve aydınlık/karanlık ortamlarda en yüksek çimlenme oranına sahip 2000 ppm giberellik asit uygulaması ile 500, 1000 ppm giberallik asit ile sülfürik asit uygulamasının $120 \mathrm{~s} 15$ dakika uygulaması (karanlık ve aydınlık/karanlık ortamlarda sülfürik asitin 15 dakika uygulamaları hariç) istatistiki olarak aynı grup içerinde yer almıştır. Giberellik asit uygulamalarında uygulama dozu artıkça çimlenme oranı kontrole göre \%50'nin üzerinde artmıştır. Giberellik asitin tohum çimlenmesini teşvik edici etkisi birçok araştırıcı tarafından bildirilmiştir (Karssen ve ark., 1989; Karssen, 1995; Sharma ve ark., 2004) ve giberellik asit tüm çimlenme karakterlerini artırarak çimlenmeyi uyarabildiğini belirtmektedir (Nadjafi ve ark., 2006). Giberellik asit uygulaması, birçok bitki türünde düşük tohum çimlenebilirliğinin üstesinden gelmek için kullanılmıştır (Kırmızı ve ark., 2011; Güleryüz ve ark., 2011; Arslan ve ark., 2011; Dar ve ark., 2009; Golmohammadzadeh ve ark., 2015). Bu çalışmada da benzer şekilde sonuçlar elde edilmiştir.

Giberellik asit uygulamalarını çimlenme oranı bakımından sülfürik asit uygulamaları takip etmiştir. Tohumların sülfürik asit içerinde 120 saniye bekletilip, aydınlık/karanlık ortamda bekletilmesi ile \%68 oranında bir çimlenme sağlanmıştır. Corchorus olitorius L. tohumlarına farklı sürelerde sülfürik asit uygulamalarının da çimlenmeyi uyardığ bildirilmektedir (Velempini ve ark., 2003; Emongor ve ark., 2004). Sülfürik asit uygulamalarında ise 15 dakika bekletilmeden sonra çimlenme oranlarında düşüşler tespit edilmiştir. Sülfürik asitte bekletme süresi 60 saniyeden 15 dakikaya çıkınca aydınlık ortamda çimlenme oranı artarken, 15 dakikanın üzerindeki bekletmelerde çimlenme oranları \%20'nin altına düşmüştür. Bu durum uzun süre sülfürik asit çözeltisi içerinde kalan tohumların asidin yakıcı özelliğinden dolayı embriyosunun zarar görebileceği sonucunu ortaya çıkarmaktadır. Tuncer ve Ummuhan (2017), molehiya (Corchorus olitorius L.) tohumlarındaki dormansi problemini çözmek için yaptıkları çalışmada tohumlara 5-10 dakika süreyle sülfürik asit (\% 98'lik) uygulamasından yüksek oranda çimlenme sağlandığını, ancak sürenin artmasıyla birlikte çimlenme değerlerinde istatistik olarak ciddi azalışlar olduğunu tespit etmişlerdir. Benzer bir başka çalışmada, Elias ve Al-Safadi (2011) sadece sülfürik asit kullanılarak yapılan uygulamaları kıyaslamışlar ve Capparis spinosa L.'da en yüksek çimlenme oranını (\%32) 20 dakika sülfürik asit ön uygulamasından elde etmişlerdir. 30 dakika sülfürik asitte bu oran düşüş göstermiş 45 ve 60 dakika sülfürik asit uygulamalarında ise hiç çimlenme gerçekleşmemiştir. $\mathrm{Bu}$ araştırma sonuçlarında da benzer şekilde sülfürik asitte bekletilme süresi arttıkça çimlenme oranlarında azalma olduğu belirlenmiştir.

Farklı ortamlarda saf suda bekletildiğinde aydınlık ortamda karanlık ve aydınlık/karanlık ortama göre daha yüksek oranda çimlenme elde edilmiştir. Her üç ortamda da tohumlarin saf suda 72 saate kadar bekletilmesinde çimlenme oranında artış görülürken 72 saatten sonra çimlenme oranında önemli düşüşler olmuştur. Obalı (2009) adi soda otunun tohumlarının farklı sürelerde su içerisinde bekleterek çimlenme oranlarını tespit ettiği çalışmada da 72 saate kadar suda bekletilen tohumlarda çimlenme oranının artığını, bu saatten sonraki uygulamalarda ise çimlenme oranının azaldığını bildirmiştir. Tohumların uzun süre durgun suda bekletilme işlemi çimlenme üzerinde olumsuz etki yaptığını Obalı (2009) ve Yazlık ve Üremiş (2015)'in yaptığı çalışmalara benzer şekilde bulunmuştur.

$\% 0.5$ lik sodyum hipokloritte bekletildikten sonra aydınlık, karanlık, aydınlık/karanlık ortamlara bırakılan tohumlarda birbirine yakın çimlenme oranı görülmüş ve bekletme süresi uzadıkça her 3 ortama bırakılan tohumlarda çimlenme oranında artış tespit edilmiştir. En yüksek çimlenme oranına 120 saat $\% 0.5^{\prime}$ lik sodyum hipokloritte bekletildikten sonra aydınlık ortama alınan tohumlardan \%55'lik çimlenme oranından sağlanmıştır. Kontrolle kıyaslandığında \%20 oranında çimlenmede bir artış gözlenmiştir. Karanlık ortamda aynı şekilde bir artış söz konusudur. 
Çizelge 1. Değişik uygulamaların aydınlık, karanlık, aydınlık/karanlık ortamda Salvia verticillata tohumların çimlenmesi üzerine etkileri (\%)

\begin{tabular}{|c|c|c|c|c|}
\hline \multirow[b]{2}{*}{ Uygulamalar } & \multirow[b]{2}{*}{ Uygulama Süresi } & \multicolumn{3}{|c|}{ Ortam } \\
\hline & & Aydınlık & Karanlık & $\begin{array}{l}\text { Aydınlık/ } \\
\text { Karanlık }\end{array}$ \\
\hline \multirow{3}{*}{$\mathrm{Saf} \mathrm{Su}$} & 24 saat & 37.0 & 27.0 & 34.5 \\
\hline & 72 saat & 43.5 & 28.5 & 34.0 \\
\hline & 120 saat & 22.0 & 19.0 & 15.5 \\
\hline \multirow{3}{*}{ Sodyum Hipoklorit (\%0.5) } & 24 saat & 30.0 & 28.0 & 29.5 \\
\hline & 72 saat & 45.5 & 44.0 & 37.5 \\
\hline & 120 saat & 55.0 & 47.0 & 39.0 \\
\hline \multirow{3}{*}{ Sodyum Hipoklorit (\%15) } & 10 dakika & 0.0 & 21.0 & 21.0 \\
\hline & 20 dakika & 37.0 & 41.0 & 28.0 \\
\hline & 60 dakika & 46.0 & 51.0 & 48.0 \\
\hline \multirow{3}{*}{ Etanol (\%96) } & 30 dakika & 20.5 & 0.0 & 24.5 \\
\hline & 60 dakika & 24.5 & 21.0 & 28.0 \\
\hline & 120 dakika & 0.0 & 0.0 & 0.0 \\
\hline \multirow{3}{*}{ Etanol (\%3) } & 24 saat & 43.5 & 34.0 & 41.0 \\
\hline & 72 saat & 34.0 & 35.5 & 38.5 \\
\hline & 120 saat & 47.5 & 53.0 & 44.0 \\
\hline \multirow{5}{*}{ Mikrodalga $120 \mathrm{~W}$ (watt) } & $10 \mathrm{~s}$ & 36.0 & 38.5 & 33.5 \\
\hline & $20 \mathrm{~s}$ & 48.0 & 58.0 & 53.0 \\
\hline & $45 \mathrm{~s}$ & 35.0 & 28.0 & 22.0 \\
\hline & $90 \mathrm{~s}$ & 27.0 & 23.0 & 19.0 \\
\hline & $180 \mathrm{~s}$ & 12.0 & 8.0 & 11.0 \\
\hline \multirow{4}{*}{ Hidroklorik Asit (\%32) } & 5 dakika & 35.5 & 34.0 & 33.5 \\
\hline & 15 dakika & 46.0 & 44.0 & 46.0 \\
\hline & 30 dakika & 36.0 & 41.0 & 42.0 \\
\hline & 60 dakika & 5.0 & 0.0 & 15.0 \\
\hline \multirow{4}{*}{ Sülfürik asit } & $60 \mathrm{~s}$ & 45.5 & 44.0 & 54.0 \\
\hline & $120 \mathrm{~s}$ & 64.0 & 61.0 & 68.0 \\
\hline & 15 dakika & 66.0 & 55.0 & 53.0 \\
\hline & 30 dakika & 19.0 & 15.5 & 11.0 \\
\hline \multirow{4}{*}{ Gibberellik asit } & $250 \mathrm{ppm}$ & 55.0 & 58.0 & 57.0 \\
\hline & $500 \mathrm{ppm}$ & 63.0 & 64.0 & 61.0 \\
\hline & 1000 ppm & 61.0 & 67.5 & 64.0 \\
\hline & $2000 \mathrm{ppm}$ & 67.0 & 74.0 & 71.0 \\
\hline Kontrol & - & 31.5 & 28.5 & 30.5 \\
\hline $\operatorname{LSD}_{0.05}$ & - & 10.4 & 11.1 & 12.5 \\
\hline Önem seviyesi & - & $* *$ & $* *$ & $* *$ \\
\hline
\end{tabular}

**Önem seviyesi $\mathrm{P}<0.01$

\%15'lik sodyum hipokloritte bekletildikten sonra aydınlık, karanlık, aydınlık/karanlık ortama birakılan tohumlarda bekletme süresi artıkça çimlenme oranında artış görülmüştür. 10 dakika $\% 15$ 'lik sodyum hipokloritte bekletilen tohumlarda kontrole göre her üç ortamda da çimlenme oranında bir düşüş olurken 10 dakikadan sonra çimlenme oranında artış tespit edilmiştir. En yüksek çimlenme oranı \%15'lik sodyum hipokloritte 60 dakika bekletildikten sonra karanlık ortama birakılan tohumlardan alınırken en düşük çimlenme oranına ise $\% 15^{\prime}$ lik sodyum hipokloritte 10 dakika bekletildikten sonra karanlık, aydınlık/karanlık ortamlarından alınmıştır. \%15'lik sodyum hipokloritte 10 dakika bekletildikten sonra aydınlık ortama birakılan tohumlarda ise herhangi bir çimlenme olmamıştır.

\%3'lük etanolde ise bekleme süresi uzadıkça kontrole oranla çimlenme oranında her üç ortamda da bir artış tespit edilmiştir. En düşük çimlenme oranına \%34 ile 24 saat etanolde bekletilip karanlık ortama bırakılan ve 72 saat etanolde bekletilip aydınlık ortama bırakılan tohumlardan alınırken en yüksek çimlenme oranı ise \%53 ile 120 saat bekletilip karanlık ortama 
bırakılan tohumlardan alınmıştır. \%96'lık etanolde bekletme süresi uzadıkça aydınlık, karanlık, aydınlık/karanlık ortamda herhangi bir çimlenme tespit edilmemiştir. Kontrolle kıyaslandığında \%96’lık etanolde bekletmek çimlenme oranını düşürmüştür. 30 dakika etanolde karanlık ortamda ve 120 dakika etanolde bekletilip aydınlık, karanlık, aydınlık/karanlık ortamlarına bırakılan tohumlarda çimlenmenin olmadığı belirlenmiştir.

Çizelge 1'de görüldüğü gibi kontrolle karşılaştırıldığında mikrodalgada $20 \mathrm{~s}$ bekletilme durumunda her üç ortamda da çimlenme oranı artarken, 20 saniyenin üzerine çıkan mikrodalga uygulamaların çimlenme oranlarında düşüş tespit edilmiştir. En yüksek çimlenme oranları $20 \mathrm{~s}$ mikrodalgada bekletmede aydınlık, karanlık ve aydınlık/karanlık ortamında sırasıyla \%48, \%58 ve \%53 oranında saptanmıştır. 180 saniye mikrodalgada bekletilip aydınlık, karanlık, aydınlık/karanlık ortama bırakılan tohumların çimlenme oranları sirasıyla $\% 12, \% 8$ ve $\% 11$ 'e kadar düştüğü tespit edilmiştir. Amirnia ve ark. (2014), çörek otu tohumları üzerine 10 ve 20 wat gücünde $0,15,30,45$ saniye uygulama yapılan bir çalışmada 10 ve 20 wat uygulamalarında 30 saniyeye kadar çimlenme hızının artmasından dolayı çimlenme indeksinin yükseldiğini, süre 45 saniye çıktığında çimlenme indeksinde düşüş olduğunu bildirmişlerdir. Yapılan çalışmada da 20 saniye kadar çimlenmenin artığı, bu sürenin üzerindeki sıcaklıklarda düşüş olması yapılan bu çalışma ile benzerlik göstermektedir.

Hidroklorik asit uygulamalarında ise 15 dakikaya kadar bekletmelerde her üç ortamda da çimlenme oranında artı̧̧ gözlenirken, 30 dakika ve üzerinde ise çimlenme oranında düşüş olmuştur. En yüksek çimlenme \%46 ile hidroklorik asitte 15 dakika bekletilmesinin aydınlık, aydınlık/karanlık ortamları olurken bunu \%44 ile 15 dakika bekletmenin karanlık uygulaması izlemiştir.

Deneme sonucunda $S$. verticillata tohumlarının çimlenmesi üzerine farklı uygulamalar ve ortamların (aydınlık, karanlık ve aydınlık/karanlık) $\mathrm{T}_{50}$ ve $\mathrm{T}_{90}$ (gün) değerlerine ait sonuçlar Çizelge 2'de verilmiştir. Her üç ortamda da konular arasında fark istatistiki olarak önemli bulunmuştur. Çizelge 2'de görüldüğü gibi tohumların \%50'sinin çimlenmesi için en uzun süre 6.75 gün ile $\% 96$ 'lık etanolde 30 dakika bekletilip aydınlık/karanlık ortama birakılan tohumlardan alınırken bunu 5.25 gün ile $\% 96$ 'lık etanol de 60 dakika ve \%3'lük etanolde 24 saat bekletilip aydınlık/karanlık ortama birakılan tohumlar izlemiştir. Tohumların \%50'sinin çimlenmesi için en kısa zaman ise 0.25 gün ile saf suda 72 saat bekletilip karanlık ortama bırakılan tohumlardan alınmıştır. Tohumların \%90'nının çimlenmesi için en uzun süre 8.50 gün ile 96'lık etanolde 30 dakika bekletilip aydınlık/karanlık ortama birakılan tohumlardan alınırken bunu 7.25 gün ile \%3'lük etanolde 120 saat bekletilip aydınlık/karanlık ortama birakılan tohumlar izlemiştir. Tohumların \%90'ının çimlenmesi için en kısa süre ise 0.25 gün ile 72 saat saf suda bekletilip karanlık ortama birakılan tohumlardan alınmıştır.

\%96'lık etanolde 120 dakika bekletilip aydınlık, karanlık, aydınlık/karanlık ortama bırakılan tohumlarda, \%96'llk etanolde 30 dakika bekletilip karanlık ortama birakılan tohumlar, \%15'lik Sodyum hipoklorit 10 dakika bekletilip aydınlık ortama birakılan tohumlar ile \%32'lik Sodyum hipoklorit de 60 dakika bekletilip karanlık ortama bırakılan tohumlarda da herhangi bir şekilde çimlenme gözlenmemiştir.

Mikrodalga uygulamalarında ise \%50'sinin çimlenmesi için en uzun süre 3.50 gün ile mikrodalgada 90 saniye bekletilip aydınlık ortama birakılan tohumlardan alınırken, \%90'ının çimlenmesi için en uzun süre 5.50 gün ile 10 saniye bekletilip aydınlık/karanlık ortama bırakılan tohumlardan elde edilmiştir. En kısa zaman ise 1 gün ile tohumların mikrodalgada 180 saniye bekletilip karanlık ortama bırakılmasından elde edilmiştir.

Sülfürik asit uygulamalarında tohumların \%50 sinin çimlenmesi için en uzun süre 4.25 gün ile 30 dakika bekletildikten sonra aydınlık/karanlık ortama bırakılan tohumlardan elde edilmiştir. En kısa zaman ise 0.50 gün ile yine 30 dakika bekletildikten sonra aydınlık/karanlık ortama bırakılan tohumlardan elde edilmiştir.

Tohumların \%90'ının çimlenmesi için geçen en kısa zaman 0.50 gün ile sülfürik asit uygulamasında 30 dakika bekletildikten sonra aydınlık/karanlık ortama bırakılan tohumlardan alınırken, en uzun süre ise 6.50 gün ile sülfürik asit uygulamasının 30 dakika bekletildikten sonra karanlık ortama birakılan tohumlardan alınmıştır.

Giberellik asit uygulamalarında ise konular ve ortamlar arasında istatistik olarak fark önemli çıkmamış olup tohumların $\% 90$ ve $\% 50$ çimlenmesi için gereken süreler birbirlerine çok yakın çıkmıştır (1.25 ile 3 gün arasında). Benzer şekilde hidroklorik asit uygulamalarında da çimlenme günleri birbirine yakın bulunmuş ancak 60 dakika bekletilip karanlık ortama birakilan tohumlarda ise herhangi bir çimlenme gözlenmemiştir.

\section{SONUÇ}

Bu çalışma ile sert tohum kabuğu ve müsilajlı madde bulunduran adaçayı tohumlarının dormansisini kırarak çimlenmeyi sağlayıcı en etkili yöntemler değişik ortamlarda (aydınlık, karanlık ve aydınlık/karanlık) araştırılmıştır. Çalışmalar sonucunda denenen birçok dormansi kırma yöntemi içerinde giberellik asit uygulamalarının çimlenmeyi 
Çizelge 2. Değişik uygulamaların aydınlık, karanlık, aydınlık/karanlık ortamlarında $\mathrm{T}_{50}$ ve $\mathrm{T}_{90}$ (gün) değerleri

\begin{tabular}{|c|c|c|c|c|c|c|c|}
\hline \multirow{3}{*}{ Uygulamalar } & \multirow{3}{*}{$\begin{array}{l}\text { Uygulama } \\
\text { Süresi }\end{array}$} & \multicolumn{4}{|c|}{ Ortam } & \multirow{2}{*}{\multicolumn{2}{|c|}{ Aydınlık/Karanlık }} \\
\hline & & \multicolumn{2}{|c|}{ Aydınlık } & \multicolumn{2}{|c|}{ Karanlık } & & \\
\hline & & $\mathrm{T}_{50}$ & $\mathrm{~T}_{90}$ & $\mathbf{T}_{50}$ & $\mathrm{~T}_{90}$ & $\mathrm{~T}_{50}$ & $\mathrm{~T}_{90}$ \\
\hline \multirow{3}{*}{$\mathrm{Saf} \mathrm{Su}$} & 24 saat & 1.25 & 1.50 & 0.50 & 0.50 & 1.00 & 2.25 \\
\hline & 72 saat & 1.25 & 2.25 & 0.25 & 0.25 & 0.50 & 0.50 \\
\hline & 120 saat & 1.50 & 2.00 & 2.75 & 3.75 & 2.00 & 5.25 \\
\hline \multirow{3}{*}{$\begin{array}{l}\text { Sodyum Hipoklorit } \\
(\% 0.5)\end{array}$} & 24 saat & 1.25 & 3.00 & 1.00 & 1.00 & 2.00 & 2.50 \\
\hline & 72 saat & 0.50 & 0.50 & 0.75 & 0.75 & 1.25 & 1.25 \\
\hline & 120 saat & 1.00 & 1.75 & 1.00 & 1.00 & 1.75 & 2.25 \\
\hline \multirow{3}{*}{$\begin{array}{l}\text { Sodyum Hipoklorit } \\
(\% 15)\end{array}$} & 10 dakika & 0.00 & 0.00 & 0.75 & 0.75 & 0.50 & 0.50 \\
\hline & 20 dakika & 2.00 & 2.75 & 2.00 & 2.25 & 2.00 & 2.25 \\
\hline & 60 dakika & 2.25 & 2.50 & 2.00 & 2.50 & 2.00 & 3.00 \\
\hline \multirow{3}{*}{ Etanol (\%96) } & 30 dakika & 2.25 & 2.50 & 0.00 & 0.00 & 6.75 & 8.50 \\
\hline & 60 dakika & 2.75 & 2.75 & 1.50 & 1.50 & 5.25 & 6.75 \\
\hline & 120 dakika & 0.00 & 0.00 & 0.00 & 0.00 & 0.00 & 0.00 \\
\hline \multirow{3}{*}{ Etanol (\%3) } & 24 saat & 2.25 & 5.75 & 1.50 & 1.75 & 5.25 & 5.75 \\
\hline & 72 saat & 1.50 & 3.50 & 2.75 & 3.00 & 4.25 & 4.25 \\
\hline & 120 saat & 3.50 & 5.50 & 2.50 & 5.00 & 4.75 & 7.25 \\
\hline \multirow{5}{*}{$\begin{array}{l}\text { Mikrodalga } 120 \quad \mathrm{~W} \\
\text { (watt) }\end{array}$} & $10 \mathrm{~s}$ & 1.75 & 1.75 & 2.00 & 3.50 & 3.00 & 5.50 \\
\hline & $20 \mathrm{~s}$ & 2.25 & 3.75 & 1.00 & 1.25 & 1.00 & 3.00 \\
\hline & $45 \mathrm{~s}$ & 2.75 & 3.25 & 1.00 & 1.50 & 1.25 & 2.75 \\
\hline & $90 \mathrm{~s}$ & 3.50 & 3.75 & 1.25 & 1.50 & 1.00 & 1.75 \\
\hline & $180 \mathrm{~s}$ & 2.50 & 2.75 & 1.00 & 1.50 & 1.00 & 2.00 \\
\hline \multirow{4}{*}{$\begin{array}{l}\text { Hidroklorik } \\
(\% 32)\end{array}$} & 5 dakika & 1.50 & 2.00 & 2.00 & 2.50 & 1.25 & 1.50 \\
\hline & 15 dakika & 2.00 & 2.25 & 2.00 & 2.50 & 2.00 & 2.00 \\
\hline & 30 dakika & 2.00 & 2.75 & 1.75 & 2.50 & 1.25 & 2.25 \\
\hline & 60 dakika & 2.75 & 4.00 & 0.00 & 0.00 & 3.00 & 4.00 \\
\hline \multirow{4}{*}{ Sülfürik asit } & $60 \mathrm{~s}$ & 2.75 & 3.25 & 1.00 & 1.75 & 1.00 & 1.25 \\
\hline & $120 \mathrm{~s}$ & 2.00 & 2.00 & 2.00 & 2.25 & 1.25 & 2.25 \\
\hline & 15 dakika & 2.00 & 2.50 & 1.75 & 2.00 & 2.00 & 2.00 \\
\hline & 30 dakika & 1.75 & 2.75 & 4.25 & 6.50 & 0.50 & 0.50 \\
\hline \multirow{4}{*}{ Gibberellik asit } & $250 \mathrm{ppm}$ & 2.00 & 2.50 & 1.75 & 1.75 & 1.75 & 2.00 \\
\hline & 500 ppm & 2.00 & 2.50 & 2.00 & 2.00 & 1.50 & 1.75 \\
\hline & 1000 ppm & 1.50 & 1.50 & 2.00 & 2.00 & 1.25 & 1.50 \\
\hline & 2000 ppm & 2.00 & 3.00 & 2.00 & 2.00 & 2.00 & 2.00 \\
\hline \multicolumn{2}{|l|}{ Kontrol } & 2.00 & 2.75 & 2.00 & 3.00 & 2.00 & 2.00 \\
\hline \multicolumn{2}{|l|}{$\operatorname{LSD}_{0.05}$} & 1.50 & 2.10 & 1.30 & 1.50 & 1.50 & 2.10 \\
\hline \multicolumn{2}{|l|}{ Önem seviyesi } & $* *$ & $* *$ & $* *$ & $* *$ & $* *$ & $* *$ \\
\hline
\end{tabular}

**Önem seviyesi $\mathrm{P}<0.01$ 
kontrole göre \%100'den daha fazla oranda arttırdığ ve 2000 ppm giberellik asit uygulamasının karanlık ortamda adaçayı tohumlarını en yüksek düzeyde çimlendirdiği sonucu ortaya çıkmıştır. Bu sonuçlar, ileride yapılacak çimlendirme çalışmalarına ışık tutma ve tıbbi olarak kullanılan adaçayı tohumlarından yeni fideler elde etmek için ön çimlendirme işleminde giberellik asit uygulamasının yapılmasının önemli olacağı sonucu ortaya çıkarmıştır.

\section{KAYNAKLAR}

Anonim 2017. Web Sitesi: www.bizimbitkiler. org.tr/v2/index.php\#, (Erişim Tarihi: 21.04.2017).

Amiri H 2007. Quantative and Qualative Changes of Essential Oil of Salvia bracteata Bank et Sol. in Different Growth Stages. Daru Journal of Pharmaceutical Sciences, 15(2): 79-82.

Amirnia R, Ghiyas M, Tajbakhsh M, Danesh YR 2014. Çörekotu Tohumunda Mikrodalga ile Uygulanan Biyofiziki Primingin Çimlenme ve Fide Büyümesi Üzerine Olan Etkisi. 5. Uluslararası Katılımlı Tohum Kongresi,19-23 Ekim, Diyarbakır.

Arslan H, Kırmızı S, Güleryüz G, Sakar FS 2011. Germination Requirements of Androsace villosa L. (Primulaceae). Acta Biologica Cracovensia Series Botanica, 53: 32-36.

Baskin CC, Baskin JM 1993. After-ripening Pattern During Cold Stratification of Achenes of Ten Perennial Asteraceae from Eastern North America, and Evolutionary Implication. Plant Species Biology, 8: 61-65.

Bayram E 2001. A Study on Selecting Suitable Types of the Anatolian Sage (Salvia fruticosa Mill.) in the Flora of Western Anatolia. Turkish Journal of Agriculture and Forestry, 25: 351-357.

Bu H, Du G, Chen X, Xu X, Liu K, Wen S 2008. Community-wide Germination Strategies in an Alpine Meadow on the Eastern Qinghai-Tibet Plateau: Phylogenetic and Life-History Correlates. Plant Ecology, 195:87-98.

Dar AR, Reshi Z, Dar GH 2009. Germination Studies on Three Critically Endangered Endemic Angiosperm Species of the Kashmir Himalaya, India. Plant Ecology, 200: 105-115.

Delamare APL, Moschen-Pistorello IT, Artico L, AttiSerafini L, Echeverrigaray S 2007. Antibacterial Activity of the Essential Oils of Salvia officinalis L. and Salvia triloba L. Cultivated in South Brazil. Food Chem., 100: 603-608.

Eidi A, Eidi M, Shahmohammadi P, Mozaffarian V, Rustaiyan A, Mazooji A 2011. Antidiabetic Effect of Salvia verticillata L. Aerial Parts in Normal and Streptozotocin-İnduced Diabetic Rats. International Journal of Pharmacology, 7: 66-73.
Elamin K, Abdelfatah M, Abdel Atti K, Malik H, Dousa B 2013. Effect of Feeding Processed Hyacinth Bean (Lablab purpureus) Seeds on Broiler Chick Performance. International Journal of Pure and Applied Biological Research and Sciences, 1(1): 9-14.

Elias R, Al-Safadi B 2011. Improvement of Caper (Capparis spinosa L.) Propagation Using In Vitro Culture and Gamma Irradiation. Scientia Horticulturae, 127: 290-297.

El-Keblawy A, Al-Rawai A 2005. Effects of Seed Maturation Time and Dry Storage on Light and Temperature Requirements During Germination in Invasive Prosopis juliflora. Flora, 201: 135-143.

Emongor VE, Mathowa T, Kabelo, S, 2004. The Effect of Hot Water, Sulphuric Acid, Nitric Acid, Gibberellic Acid and Ethephon on the Germination of Corchorus (Corchorus tridens) Seed. Journal of Agronomy, 3(3): 196-200.

Ghasemi Pirbaloti A, Golpror AR, Dehkordi Riahi M, Navid RA 2007. The Effect of Different Treatments on Seed Dormancy and Germination of Five Species of Medicinal Plants of Chaharmahal \& Bakhteyari province. Journal of Pajouhesh \& Sazandegi, 74: 185-192.

Golmohammadzadeh S, Zaefarian F, Rezvani M 2015. Effects of Some Chemical Factors Prechilling Treatments and Interactions on the Seed Dormancy Breaking of Two Papaver Species. Weed Biology and Management, 15: 11-19.

Güleryüz G, Kırmızı S, Arslan H, Sakar FS 2011. Dormancy and Germination in Stachys germanica L. subsp. bithynica (Boiss.) Bhattacharjee Seeds: Effects of Short-time Moist Chilling and Plant Growth Regulators. Flora, 206: 943-948.

Harley RM, Atkins S, Budantsev A, Cantino PD, Conn BJ, Grayer R, Harley MM, de Kok R, Krestovskaja T, Morales R, Paton AJ, Ryding O, Upson T 2004. Labiatae. In: Kubitzki, K. (ed.), The Families and Genera of Vascular Plants, 7: 167275.

Hazerbroek JP, Metzger JD 1990. Environmental Control of Seed Germination in Thlaspi arvense (Cruciferae). American Journal of Botany, 77: 945953.

Hilhorst HWM 1995. A Critical Update on Seed Dormancy. I. Primary dormancy. Seed Sci. Res., 5: 61-73.

Kahraman A, Celep F, Doğan M 2009. Morphoogy, Anatomy and Palynology of Salvia indica L. (Labiatae). World Applied Sciences Journal, 6 (2): 289-296.

Karssen CM, Zagorski S, Kepczynski J, Groot SPC 1989. Key Role for Endogenous Gibberellins in the Control of Seed Germination. Annals Botany, 63: 71-80. 
Karssen CM 1995. Hormonal Regulation of Seed Development, Dormancy, and Germination Studied by Genetic Control. In J Kigel, G Golili, eds, Seed Development and Germination, Marcel Dekker, New York.

Kırmızı S, Güleryüz G, Arslan H, 2011. Germination Responses to $\mathrm{GA}_{3}$ and Short-Time Chilling of Three Endemic Species: Tripleurospermum pichleri, Cirsium leucopsis and Senecio olympicus (Asteraceae). Plant Species Biology, 26: 51-57.

Khakpoor A, Bibalani GH, Mahdavi S 2015. Optimal Treatment Increased the Seed Germination of Salvia verticillata L. J. BioSci. Biotechnol., 4(3): 255-262.

Kotan R, Kordalı Ş, Çakır A, Kesdek M, Kaya Y, Kılıç $\mathrm{H}$ 2008. Antimicrobial and İnsecticidal Activities of Essential Oil İsolated from Turkish Salvia hydrangea DC. ex Benth. Biochem Sys Eco., 36: 360-368.

Kunduhoglu B, Kurkcuoglu M, Duru ME, Baser KHC 2011. Antimicrobial and Anticholinesterase Activities of the Essential Oils İsolated from Salvia dicroantha Stapf., Salvia verticillata L. subsp amasiaca (Freyn and Bornm.) Bornm. and Salvia wiedemannii Boiss. Journal of Medicinal Plants Research, 5(29): 6484-6490.

Latifi N. 2001.Techniques in Seed Science and Technology. University of Agriculture Science and Natural Resources Gorgan, 310 pp.

Matkowski A, Zielins S., Oszmians J, LamerZarawska E 2008. Antioxidant Activity of Extracts from Leaves and Roots of Salvia miltiorrhiza Bunge, S. przewalskii Maxim., and S. verticillata L., Bio Tech., 99: 7892-7896.

Mayekiso B, Magwa ML, Coopoosamy RM, 2008: The Chemical Composition and Antibacterial Activity of the Leaf Extract of Salvia repens Burch. ex Benth. JMPR, 2 (7): 159-162.

Nadjafi F, Bannayan M, Tabrizi L, Rastgoo M 2006. Seed Germination and Dormancy Breaking Techniques for Ferula gummosa and Teucricum polium. Journal of Arid Environments, 64: 542547.

Obalı A, 2009. Adi Soda Otu (Salsola kali subsp. ruthenica (Iljin) Soo.) Tohumlarının Çimlenme Biyolojisi Üzerinde Araştırmalar. Selçuk Üniversitesi. Fen Bil. Ens., Bitki Koruma ABD, Yüksek Lisans Tezi, $42 \mathrm{~s}$.

Orhan IE, Senol FS, Ercetin T, Kahraman A, Celep F, Akaydin G, Sener B, Dogan M, 2013. Assessment of Anticholinesterase and Antioxidant Properties of Selected Sage (Salvia) Species with their Total Phenol and Flavonoid Contents. Industrial Crops and Products, 41: 21-30.
Özcan İI, Arabacı O, Öğretmen NG, 2014. Bazı Adaçayı Türlerinde Farklı Tohum Çimlendirme Uygulamalarının Belirlenmesi. Türk Tarım - Gıda Bilim ve Teknoloji Dergisi, 2(5): 203-207.

Özer H 2016. Erzurum Çevresinde Doğal Yayılış Gösteren Salvia Türleri ve Tıbbi Özellikleri. Tarla Bitkileri Merkez Araştırma Enstitüsü Dergisi, 25(Özel say1-2):340-345.

Sarbanha S, Masoomi F, Kamalinejad M, Yassa N, 2011. Chemical Composition and Antioxidant Activity of Salvia virgata Jacq. and $S$. verticillata L. Volatile Oils From Iran. Planta Medica., 77(12): 1297-1298.

Sarmadnia GH 1996. Seed technology. Mashhad University, $288 \mathrm{pp}$.

Sharma AD, Thakur M, Rana M, Singh K, 2004. Effect of plant growth hormones and abiotic stresses on germination, growth and phosphatate activities in Sorghum biocolor (L.) moench seeds. African Journal of Biotechnology, 3(6), 308-312.

Temel M, 2000. Batı Anadolu Bölgesinde Yayılış Gösteren Origanum L. Türleri Üzerinde Biyosistematik Çalışmalar, ESOGÜ Fen Bilimleri Enstitüsü, Tarla Bitkileri Ana Bilim Dalı, Doktora Tezi, $219 \mathrm{~s}$.

Tepe B, Dönmez E, Ünlü M, Candan F, Daferera D, Vardar-Ünlü G, Polissiou M, Sökmen A 2004. Antimicrobial and Antioxidative Activities of the Essential Oils and Methanol Extracts of Salvia cryptantha (Montbret et Aucher ex Benth.) and Salvia multicaulis (Vahl). Food Chem., 84: 519525.

Tosun M, Ercişli S, Şengul M, Özer H, Polat T, Özturk E 2009. Antioxidant Properties and total Phenolic Content of Eight Salvia Species from Turkey. Biological Research, 42 (2): 175- 181.

Tuncer B, Ummuhan F 2017. Molehiya (Corchorus olitorius L.) tohumlarındaki Dormansi Probleminin Çözümüne Yönelik Araştırma. Turk J Agric Res., 4(3): 268-274.

Velempini P, Riddoc, I, Batısani N, 2003. Seed Treatments for Enhancing Germination of Wild Okra (Corchorus olitorius). Experimental Agriculture, 39(4): 441-447.

Yazlık A, Üremiş İ 2015. Kanyaş [(Sorghum halepense (L.) Pers.J'ın Tohum ve Rizom Biyolojisine Yönelik Çalışmalar. Derim, 32 (1):1130.

Yılmaz G, Güvenç A 2007. Morphological and Anatomical Investigation on the Herbal Drugs which Sold under the Name "Sage" in Herbalist in Ankara. Journal of the Faculty of Pharmacy of Ankara University, 36 (2): 87-104. 